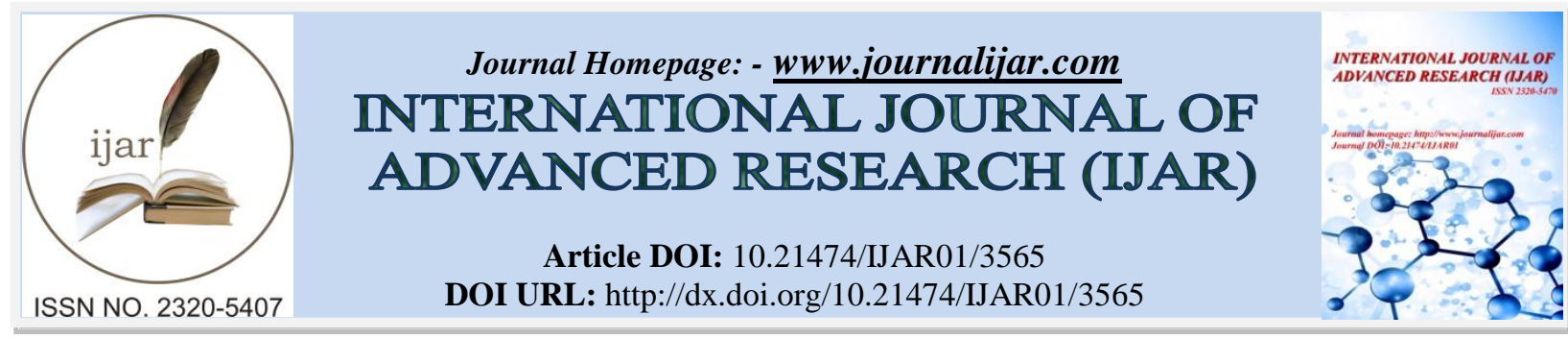

RESEARCH ARTICLE

\title{
EVALUATION OF GLOBAL LV FUNCTION AND MECHANICAL DYSSYNCHRONY IN PATIENTS WITH LEFT BUNDLE BRANCH BLOCK (LBBB) - 2D ECHOCARDIOGRAPHY, 2D SPECKLE TRACKING AND REAL TIME 3D ECHOCARDIOGRAPHY.
}

\footnotetext{
Dr Suresh V Patted ${ }^{1}$, Dr Sanjay C Porwal ${ }^{2}$, Dr Prabhu C Halkati ${ }^{3}$, Dr Sameer Ambar ${ }^{4}$, Dr Prasad M R ${ }^{5}$, Dr V.B Metgudmath ${ }^{6}$, Dr Vishwanath Hesarur ${ }^{7}$, Dr Anand Kumar $\mathbf{M}^{8}$ and Dr Shakuntala .

1. Professor and Head, Department of Cardiology, J.N .Medical College, KLE University, Belgaum , Karnataka, India-590001.

2. Associate Professor, Department of Cardiology, J.N.Medical College, KLE University, Belgaum, Karnataka, India-590001.

3. Professor, Department of Cardiology, J.N.Medical College, KLE University, Belgaum, Karnataka, India590001.

4. Associate Professor, Dept of Cardiology, J.N.Medical College, KLE University, Belgaum, Karnataka, India590001.

5. Assistant Prof, Department of Cardiology, J.N.Medical College, KLE University, Belgaum, Karnataka, India590001.

6. Assistant Prof, Department of Cardiology, J.N.Medical College, KLE University, Belgaum, Karnataka, India590001.

7. Assistant professor, Dept of Cardiology, J.N. Medical College, KLE University, Belgaum, Karnataka, India59000.

8. Senior Resident, Department of Cardiology J.N.Medical College, KLE University, Belgaum, Karnataka, India590001.

9. MSc Post Graduate, Department of Cardiology J.N.Medical College, KLE University, Belgaum, Karnataka, India-590001.
}

\section{Manuscript Info}

Manuscript History

Received: 30 January 2017

Final Accepted: 10 March 2017

Published: March 2017

Key words:-

Left bundle branch block(LBBB), Left ventricular dysfunction(LV

dysfunction),mechanical dyssynchrony,

Speckle tracking, Real time 3D

Echocardiography(RT3DE).

\section{Abstract}

Background: LBBB affects LV function and causes LV mechanical dyssynchrony. Prevalence of LBBB increases with age about $0.05 \%$ to $5.7 \%$ between age of 30-80 years in otherwise healthy population. Aim of the study was to evaluate the LV function and mechanical dyssynchrony with 2D Echocardiography, 2D speckle tracking and real time 3D Echocardiography (RT3DE) in asymptomatic LBBB patients, non- LBBB volunteers, and with symptomatic LBBB patients.

Methods: 2D Echocardiography, 2D speckle tracking and real time 3D Echocardiography was performed in 191 patients, 65 were non- LBBB volunteers, 60 patients were asymptomatic LBBB and 66 patients were symptomatic LBBB patients. Global LV function and mechanical dyssynchrony were measured.

Results: Non LBBB volunteers mean LV ejection fraction by 2D Echo was 67.18 $\pm \mathrm{SD} 3.45$, in RT3DE mean LV ejection fraction was 61.88 \pm SD 3.12. In asymptomatic LBBB patients LVEF by $2 \mathrm{D}$ was $58.43 \pm$ and RT3DE LVEF was $54.47 \pm 4.08$. In heart failure (HF) with LBBB patients 2D LVEF was 43.53 \pm 7.12 and 3D LVEF 39.21 \pm 7.97 .

Corresponding Author:- Dr. Suresh V Patted.

Address:- Professor and Head, Department of Cardiology, J.N.Medical College, Belgaum, Karnataka, India-590001. 
LV dyssynchrony measurements by 2D speckle tracking analysis showed:

A. Sdt of $6 \mathrm{~S}$ segments by $\mathrm{CS}$ was $54.82 \pm 11.2,96.43 \pm 17.73$, $119.02 \pm 23.17$ for non-LBBB volunteers, asymptomatic LBBB patients and symptomatic LBBB patients respectively.

B. Sdt of $12 \mathrm{~S}$ by LS was $52.96 \pm 5.1,90.03 \pm 16.2,111.75 \pm 34.22$ for non-LBBB volunteers, asymptomatic LBBB patients and symptomatic LBBB patients respectively.

Systolic dyssynchrony (SDI) index by RT3DE was 5.07 \pm 2.22 , 7.44 \pm $1.45,15.08 \pm 3.85$ for non-LBBB volunteers, asymptomatic LBBB patients and symptomatic LBBB patients respectively.

Conclusion: Asymptomatic LBBB patients have more depressed LV function than non LBBB volunteers with intermediate mechanical dyssynchrony, symptomatic LBBB patients have moderate to severe LV dysfunction and most severe mechanical dyssynchrony among the 3 groups.

Copy Right, IJAR, 2017,. All rights reserved.

\section{Introduction:-}

Left ventricular (LV) mechanical dyssynchrony is observed in left bundle branch block (LBBB). Persistent mechanical dyssynchrony contributes to progressive ventricular remodelling and impaired systolic LV function. ${ }^{1}$ Mechanical dyssynchrony may partially be responsible for the increased morbidity and mortality in heart failure (HF) patients with conduction abnormalities as a LBBB, compared to patients without a LBBB. ${ }^{2-5}$

In patients without underlying structural cardiac disease, except the presence of a LBBB, subtle impaired systolic and diastolic LV functions are frequently found. ${ }^{6}$ However, impaired function in these patients is not always recognized because of lack of clinical symptoms. ${ }^{6-8}$

Prevalence of LBBB increases with age about $0.05 \%$ to $5.7 \%$ between age of $30-80$ years in otherwise healthy population. ${ }^{24-26}$ Currently, the most widely used methods for the clinical assessment of LV function and mechanical dyssynchrony are two-dimensional (2D) echocardiography and tissue Doppler imaging. ${ }^{9-11}$

Speckle tracking strain analysis method based on grayscale 2-dimensional (2D) images, and transthoracic real-time three- dimensional echocardiography (RT3DE) are relatively novel imaging technique which offers the unique opportunity to evaluate global LV function fast and accurate, without presumptions and with comparable results as 2D Echocardiography and magnetic resonance imaging. ${ }^{12-15}$ In addition, combined with specially designed software, provides detailed quantitative information of mechanical dyssynchrony. ${ }^{16-18}$

Therefore, we designed a prospective cross-sectional study to assess global LV function and mechanical dyssynchrony in consecutive LBBB patients. The first purpose of this study was to evaluate global LV function and the amount of mechanical dyssynchrony by Speckle tracking strain analysis and RT3DE in asymptomatic LBBB patients compared to non- LBBB volunteers and patients with symptomatic LBBB. The second purpose was to evaluate the association between LV mechanical dyssynchrony and the presence or absence of symptoms of HF.

\section{Methods:-}

LBBB was diagnosed according to standard electrocardiography criteria: A QRS duration greater than $120 \mathrm{ms,}$ absence of initial septal Q waves, a broadened $\mathrm{R}$ wave in the left precordial leads, and an initial $\mathrm{R}$ wave followed by a wide, deep S wave in the right precordial leads on a 12-lead electrocardiogram. Symptoms of HF included dyspnoea, ankle oedema, fatigue and reduced exercise tolerance.

Consecutive OPD and IPD patients of LBBB attending to our department of Cardiology were included as per inclusion criteria. Ethical committee clearance was taken. 
There are very few studies quantifying LV volume, ejection fraction and mechanical dyssynchrony in patients with LBBB by 2D Echocardiography, 2D speckle tracking, real time 3D echo, hence we have taken up this study.

One hundred and ninety one subjects were studied, consisting of sixty five volunteers with no abnormal findings during physical examination, no conduction abnormalities on electrocardiogram; sixty consecutive asymptomatic LBBB patients, with no history of structural cardiac disease and no abnormal findings during physical examination, New York Heart Association function class (NYHA) I and sixty-six consecutive symptomatic LBBB patients, NYHA II-III, without pulmonary hypertension, were screened.

ECG gated echocardiography was performed using EPI Q 7C (Philips Medical Systems, Andover, Mass), installed with highly advanced software techniques are used for 2D echocardiography, 2D speckle tracking with strain imaging, real time 3D Echocardiography image acquisitions. A matrix array transducer with a frequency range from 2 to $5 \mathrm{mhz}$, and the transducer was maintained in a fixed orientation. A complete examination of patients with normal conduction and those with LBBB was performed

\section{Quantification of LV function:- \\ Dimensional echocardiographic LV volume and LVEF by modified Simpson's method:-}

Transthoracic apical 4-chamber view was performed, later Left ventricular end diastolic image and Left ventricular end systolic images were acquired, and in the same way apical 2-Chamber Left ventricular end diastolic image and Left ventricular end systolic ECG gated images were acquired with patient in left lateral decubitus position. Then LV end diastolic volume, LV end systolic volumes, LVEF was estimated in apical 4- and apical 2-chamber windows by the modified Simpson's method.

The volume of the LV is calculated from the dimension and area obtained from orthogonal apical views (fourchamber and two-chamber views). The LV volume was then calculated with the modified Simpson method or disk summation method

Three -Dimensional data acquisition and Analysis:-

Three-dimensional echocardiography, first as reconstructed images and more recently as real-time acquisition, provides reproducible assessment of LV volumes, dimensions and systolic function. Using dedicated reconstruction software, semi-automated border detection allows continuous volume calculation of all 16 myocardial segments simultaneously. Represented as regional volumetric curves during the cardiac cycle, the timing of minimal volume for each segment can be analyzed. With normal homogeneous activation, the different LV segments reach their minimal volume at the same time.

Transthoracic apical 4-chamber full volume acquisitions were made during $4-6 \mathrm{~s}$ breath-hold, with the patient in left lateral position. Care was taken to include the entire LV volume within the pyramid shaped 3D scan-volume. Due to the sector width of the acquired volume, three alternate heart cycles and a constant R-R interval were obligatory or compulsory to create a full-volume acquisition of the LV.

Then apically acquired dataset was imported into an offline software package for analysis.

$>$ Identification of three points or land marks i, e mitral valve, aortic valve and apex was done, then the volume data set was automatically sliced into eight equally rotated imaging planes, in this end systolic frame and end diastolic frames were identified.

$>$ After identification of end systolic frame and end diastolic frames, the apex and two annulus points were determined in both end diastolic and end systolic state.

$>$ Later endocardial borders were traced in end-diastole using an automated counter detection software system, in case the borders were not accurate, manually these endocardial borders were manipulated and adjusted, then a full volume 3-D model of the left ventricle was reconstructed.i.e a LV cast is formed.

$>$ After a full volume 3D model of the left ventricle was reconstructed, the left ventricle was divided into 16segments, then segmental analysis was performed, later end diastolic end systolic volumes and ejection fraction were displayed on screen along with this global and segmental volume and EF were presented.

Quantification of left ventricular mechanical dyssynchrony:Real time 3D Echo:- 
LV cast was divided into 16 pyramid-shaped segments. For each segment, a regional time-volume curve was obtained and the systolic dyssynchrony index (SDI) was derived. From the regional time-volume curves, the systolic dyssynchrony index (SDI) was derived. ${ }^{20}$ SDI is based on the standard deviation of mean time-to-minimal regional volume of $16 \mathrm{LV}$ segments (six basal, six mid-segments and four apical segments) during a cardiac cycle. In other words, SDI is the dispersion of time-to-minimal regional volume for all $16 \mathrm{LV}$ segments. Time is represented as percentage of the RR interval to allow comparisons of different patients which otherwise could be influenced by RR interval duration.

\section{Speckle tracking strain Analysis:-}

Standard grayscale 2D images were acquired in the 2- and 4-chamber apical views as well as the parasternal and short-axis views. From an end-systolic single frame, a region of interest was traced on the endocardial cavity interface by a point-and-click approach. Then an automated tracking algorithm followed the endocardium from this single frame throughout the cardiac cycle. Further adjustment of the region of interest was performed to ensure that all of the myocardial regions were included. Speckles, equally distributed in the region of interest, could be followed throughout the entire cardiac cycle. The distance between the speckles was measured as a function of time, and parameters of myocardial deformation could be calculated.

Myocardium was divided into 6 segments that were color coded and displayed into 6 segmental time-strain curves for CS, and LS. ${ }^{27}$

\section{Two different parameters for dyssynchrony were obtained:-}

\section{Circumferential Strain (CS)}

$>$ Difference between time to peak-systolic strain of the (antero) septal and posterior segments (AS-P delay). Figure B

$>$ The standard deviation of time to peak-systolic strain for all 6 segments (sdt6s) was measured.

Figure B:- Difference between time to peak-systolic strain of the (antero) septal and posterior segments (AS-P delay) by circumferential strain.

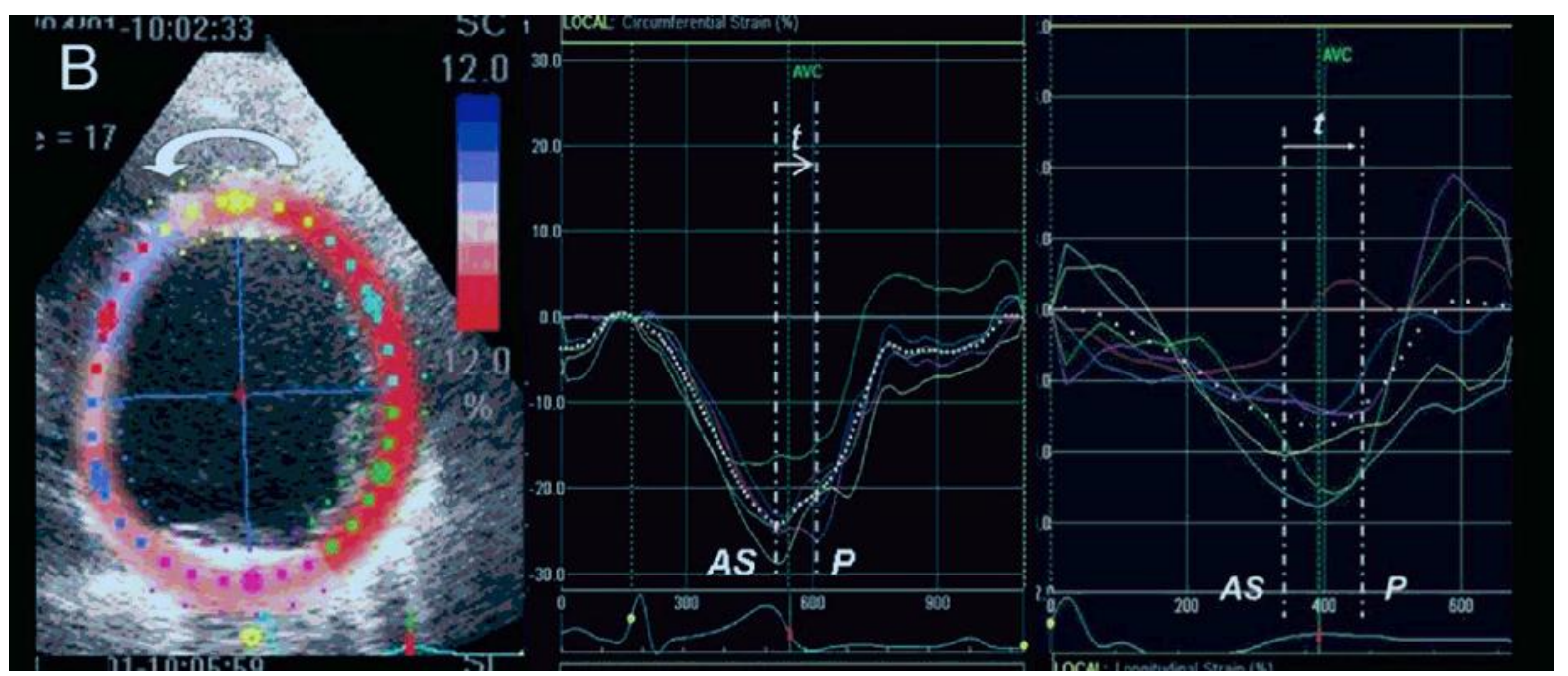

Longitudinal Strain (Ls):-

$>$ Difference between time to peak-systolic strain of the basal-septal and basal-lateral LV segment (BS-BL delay). Figure C

$>$ The standard deviation of time to peak-systolic strain for $12 \mathrm{LV}$ segments (sdt12s)

Figure C:- Difference between time to peak-systolic strain of the basal-septal and basal-lateral LV segment (BS-BL delay) by longitudinal strain. 


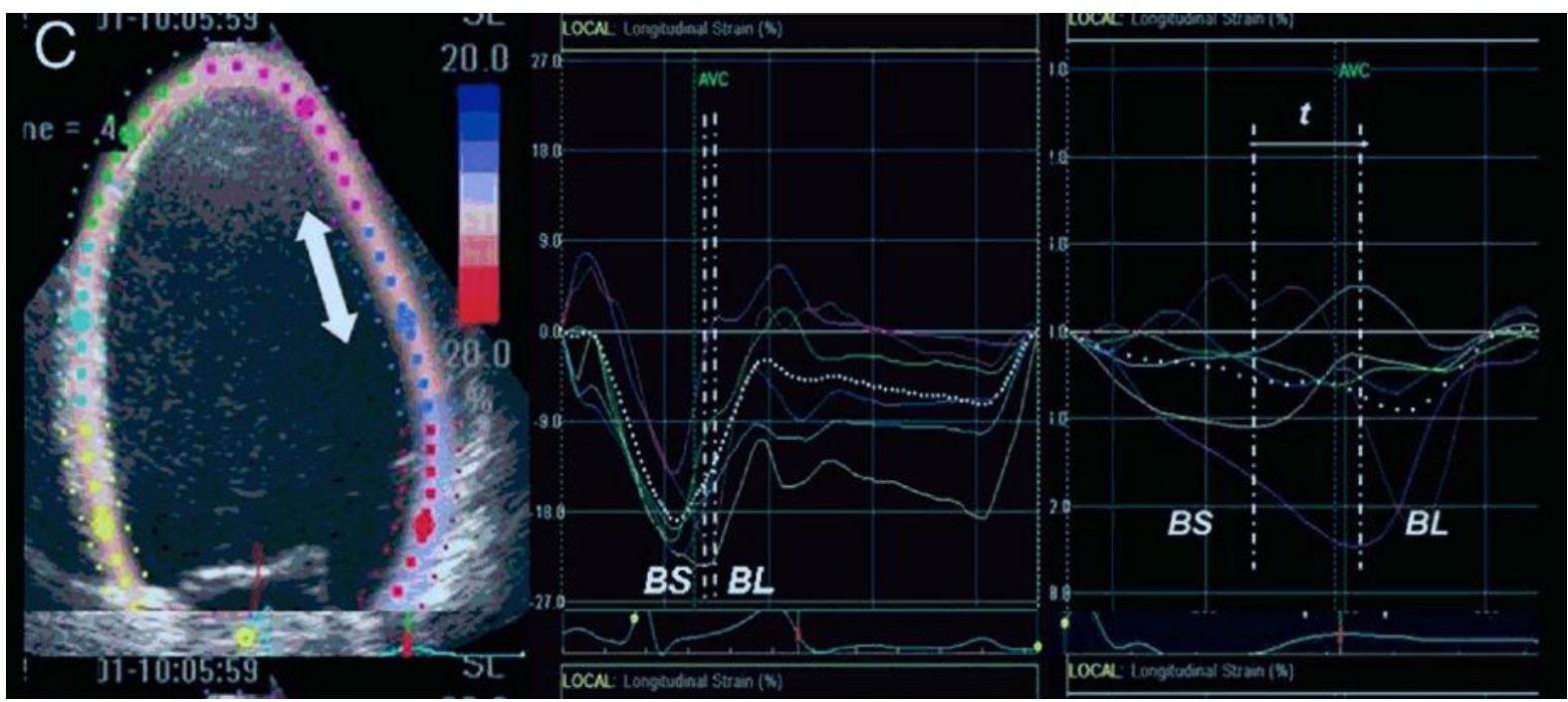

Statistical Analysis:-

Data are expressed as mean value \pm standard deviation(SD). For comparison of means between the three groups, a one way ANOVA test with Tukeys multiple posthoc analysis was used. A probability value of $p<0.05$ was considered as statistically significant.

\section{Results:-}

\section{Subjects:-}

A total of 191 consecutive LBBB patients and non- LBBB volunteers were enrolled. The final study population consisted of Sixty five non LBBB volunteers (mean age $51 \pm 7$ years, QRS duration $96 \pm 4$ ms), sixty patients with an

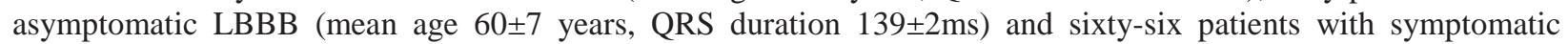

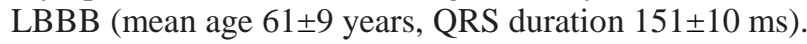

QRS duration of both asymptomatic LBBB and symptomatic LBBB groups was significantly more compared to non- LBBB volunteers ( $\mathrm{p}=0.0001)$

Then further comparing QRS duration of symptomatic LBBB patients and asymptomatic LBBB it was observed that symptomatic LBBB patients had more QRS duration. ( $\mathrm{p}=0.0001)$. Table 1

Table 1:- Patient characteristics.

\begin{tabular}{|l|l|l|l|l|}
\hline & $\begin{array}{l}\text { Non- LBBB } \\
\text { volunteers }\end{array}$ & Asymptomatic LBBB & Symptomatic LBBB & P value \\
\hline Number $(\mathrm{n})$ & 65 & 60 & 66 & - \\
\hline Male, $\mathrm{n}(\%)$ & $34(52.35)$ & $17(28.33)$ & $48(65.15)$ & - \\
\hline Age & $51 \pm 7$ & $60 \pm 7$ & $61 \pm 9$ & - \\
\hline NYHA class & & I & II-III & - \\
\hline QRS duration & $96.14 \pm 4.22$ & $139.67 \pm 1.81^{*}$ & $151.75 \pm 10.09 \dagger, \#$ & $<0.0001$ \\
\hline Hypertension, $\mathrm{n}$ & 13 & 18 & 22 & - \\
\hline Diabetics, $\mathrm{n}$ & 10 & 21 & 24 & - \\
\hline Diuretics $\mathrm{n}$ & - & 6 & 66 & - \\
\hline Beta blockers, $\mathrm{n}$ & - & 4 & 62 & - \\
\hline ACE/ ARB, $\mathrm{n}$ & 10 & 15 & 46 & - \\
\hline Statin, $\mathrm{n}$ & 10 & 14 & 56 & - \\
\hline Antiplatelet agents, $\mathrm{n}$ & 10 & 20 & 64 & - \\
\hline
\end{tabular}

LBBB, left bundle branch block; NYHA, New York Heart Association function class; ACEI, ACE inhibitor; ARB, angiotensin receptor blockade;

* Significant difference non-LBBB volunteers versus Asymptomatic LBBB.

$\uparrow$ Significant difference non- LBBB volunteers versus symptomatic LBBB.

\# Significant difference asymptomatic LBBB versus symptomatic LBBB. 


\section{Global LV function:-}

2D Echocardiography by Simpsons method

EF, ESV and EDV in both asymptomatic LBBB and symptomatic LBBB patients when compared to non- LBBB volunteers was significantly low $(\mathrm{p}=0.0001)$

Then when EF, ESV and EDV in symptomatic LBBB compared to asymptomatic LBBB was significantly lower $(\mathrm{p}=0.001)$ Table 2

Real time 3D Echocardiography parameters:-

EF, ESV and EDV values showed same results of significant difference when compared among the 3 groups as in 2D Echocardiography. Table 2

\section{Comparing ESV, EDV, EF values of 2D and 3D Echocardiography:-}

Comparison of EDV, EF values on 2D and 3D Echocardiography of all the 3 groups showed that real time 3D echocardiographic values were lesser, which was statistically significant. $(p=0.0001)$

Comparison of ESV values on 2D and 3D Echo was also statistically significant and lesser by real time 3D echocardiography in non-LBBB volunteers and symptomatic LBBB groups $(\mathrm{p}=0.0001)$

But comparison of ESV values on 2D and 3D Echo in asymptomatic LBBB was not significant (0.254). Table 2.

Table 2:- Global LV function.

\begin{tabular}{|c|c|c|c|c|}
\hline \multicolumn{2}{|l|}{ Groups } & 2D Echo & RT3D E & $\mathrm{P}$ value \\
\hline \multirow[t]{3}{*}{ Non-LBBB } & LVEF & $67.18 \pm 11.05$ & $61.88 \pm 3.13 *+\dagger$ & $<0.0001$ \\
\hline & LVEDV & $58.75 \pm 7.79$ & $47.77 \pm 7.92 *+\dagger$ & $<0.0001$ \\
\hline & LVESV & $25.25 \pm 4.47$ & $21.69 \pm 3.84 *+\dagger$ & $<0.0001$ \\
\hline \multirow{3}{*}{$\begin{array}{l}\text { Asymomatic } \\
\text { LBBB }\end{array}$} & LVEV & $58.43 \pm 2.63$ & $54.47 \pm 4.08 *+\dagger$ & $<0.0001$ \\
\hline & LVEDV & $76.02 \pm 11.58$ & $70.52 \pm 7.71 *$ * & $<0.0001$ \\
\hline & LVESV & $30.68 \pm 5.33$ & $31.52 \pm 3.50+\dagger$ & $0.254,0.0001+\dagger$ \\
\hline \multirow{3}{*}{$\begin{array}{l}\text { Symptomatic } \\
\text { LBBB }\end{array}$} & LVEV & $43.53 \pm 7.12$ & $39.21 \pm 7.97 *+\dagger$ & $<0.0001$ \\
\hline & LVEDV & $97.44 \pm 37.84$ & $84.53 \pm 30.74 * t+\#$ & $<0.0001$ \\
\hline & LVESV & $58.42 \pm 29.49$ & $49.17 \pm 25.39^{*}+\dagger$ & $<0.0001$ \\
\hline
\end{tabular}

LBBB- Left bundle branch block; Lv- Left ventricle; EF- Ejection fraction; EDV- end-diastolic volume; ESV- endsystolic volume; 2D- 2-dimensional Echocardiography; RT3DE- Real time 3-dimensional Echocardiography. $\$$ Significant difference non-LBBB volunteers versus Asymptomatic LBBB.

$\dagger$ Significant difference non- LBBB volunteers versus symptomatic LBBB.

\# Significant difference asymptomatic LBBB versus symptomatic LBBB

* Significant difference 2D Echo versus RT3D Echo.

\section{Quantification of LV mechanical dyssynchrony:-}

\section{Real time 3D Echo:-}

Mean SDI of both groups asymptomatic LBBB (7.44 \pm 1.45$)$ and symptomatic LBBB (15.08 \pm 3.85$)$ was statistically significant and more when compared to non- LBBB volunteers $(5.07 \pm 2.22)(\mathrm{p}=0.0001)$ and mean SDI of symptomatic LBBB was more and statistically significant than asymptomatic LBBB ( $\mathrm{p}=0.0001)$. Table 3, Figure A, Figure 1.

Figure A:- Regional time-volume curve and systolic dyssynchrony index by RT3DE 


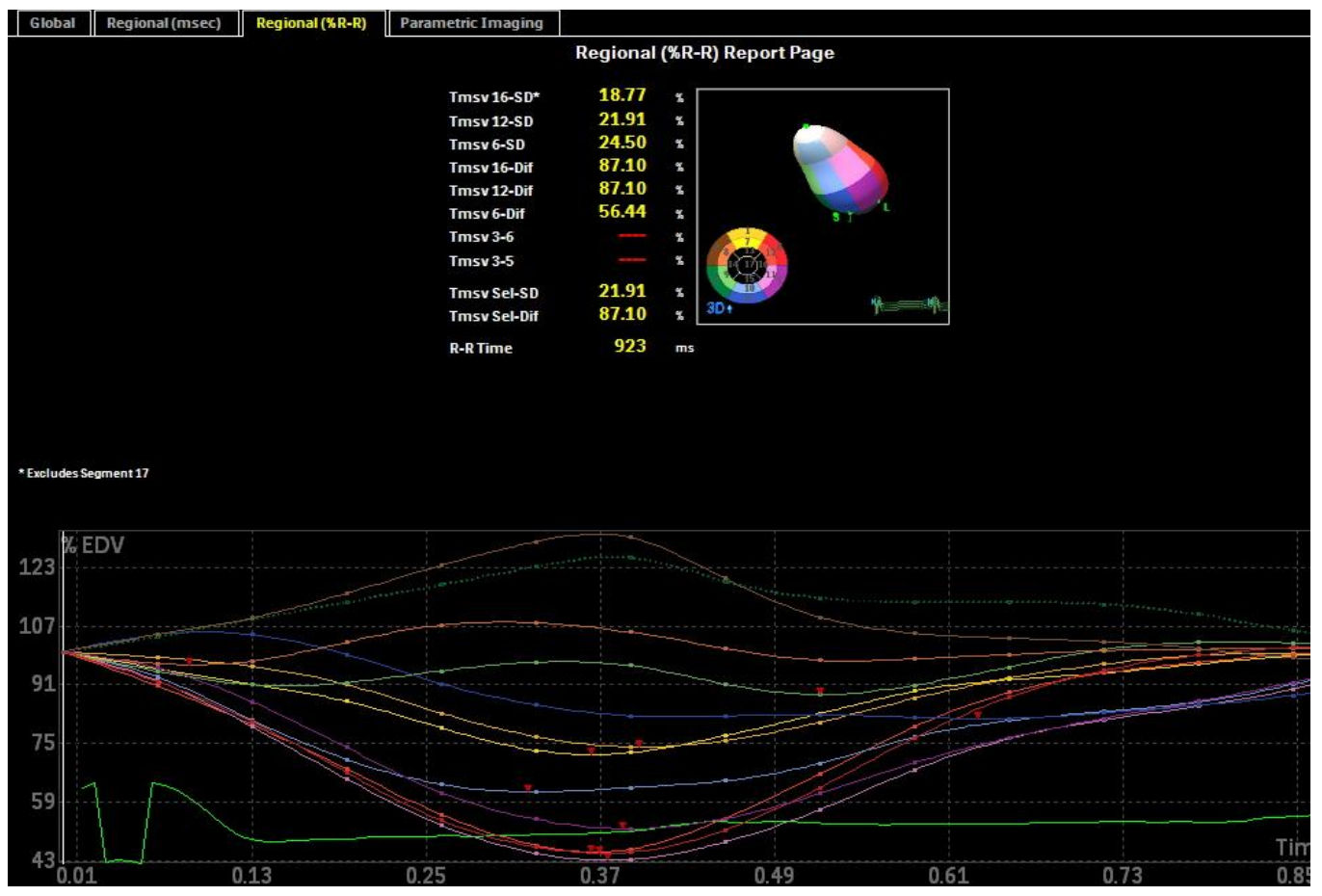

Figure 1:Comparison of three groups (symptomatic LBBB, asymptomatic LBBB and non-LBBB volunteers) with mean SDI scores

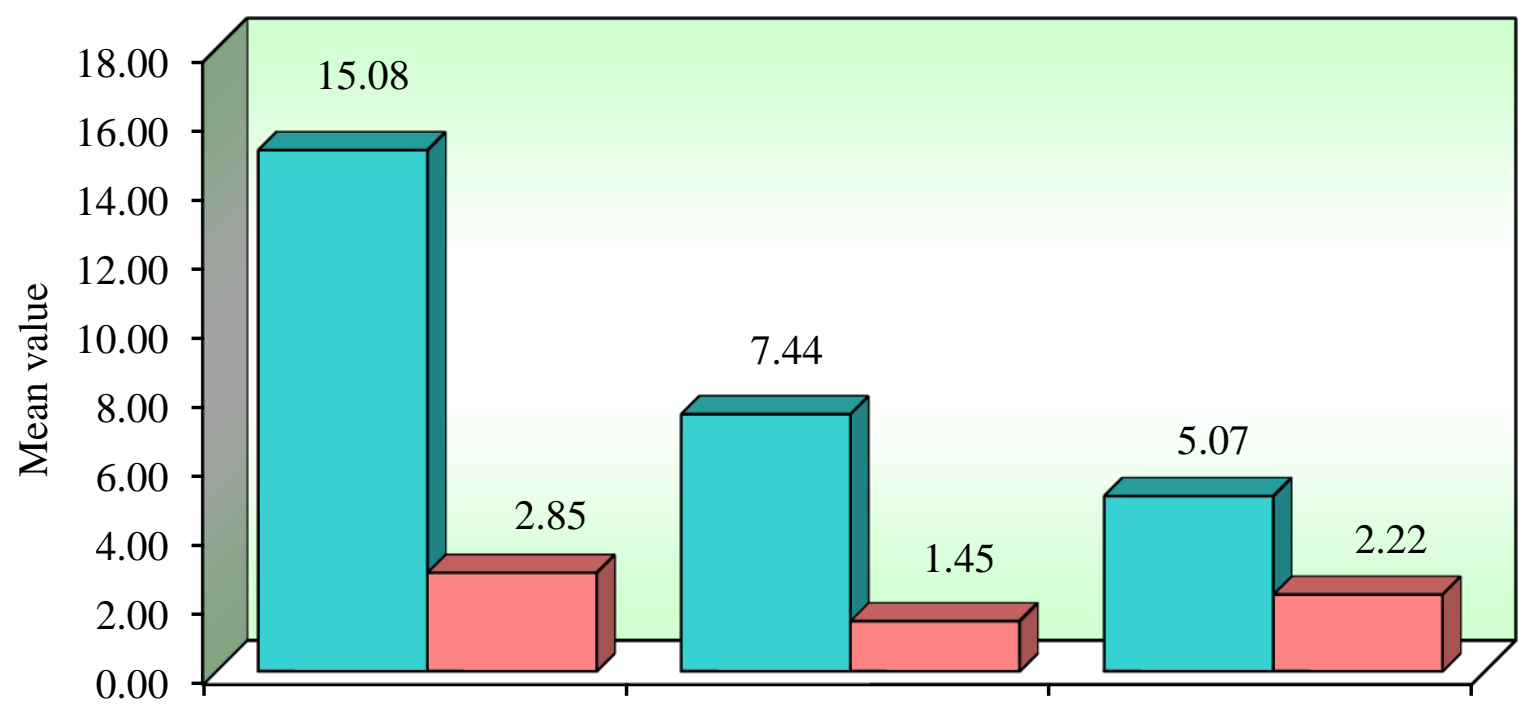

symptomatic LBBB Asymptomatic LBBB non-LBBB volunteers

\begin{tabular}{|l|l}
\hline Mean & $\square \mathrm{SD}$ \\
\hline
\end{tabular}

Speckle tracking strain Analysis:-

AS- P delay and sdt6s as assessed by CS and BS- BL delay and sdt12s assessed by LS were significantly more in asymptomatic LBBB and symptomatic LBBB patients when compared to non- LBBB volunteers $(\mathrm{p}=0.0001)$. 
Further when asymptomatic LBBB patients and symptomatic LBBB patients were compared for these parameters, symptomatic LBBB patients had significantly more LV dyssynchrony ( $\mathrm{p}=0.0001)$. Table 3, Figure D, Figure 2,3.

Table 3:- Mechanical dyssynchrony.

\begin{tabular}{|l|l|l|l|l|}
\hline & $\begin{array}{l}\text { Non- LBBB } \\
\text { volunteers }\end{array}$ & Asymptomatic LBBB & Symptomatic LBBB & P value \\
\hline SDI(\%) & $5.07 \pm 2.22$ & $7.44 \pm 1.45^{*}$ & $15.08 \pm 3.85 \dagger, \#$ & $<0.0001$ \\
\hline AS-PS delay by CS & $46.2 \pm 11.30$ & $73.65 \pm 23.01^{*}$ & $133.80 \pm 40.95 \dagger, \#$ & $<0.0001$ \\
\hline Sdt 6 s by CS & $54.88 \pm 11.29$ & $96.43 \pm 17.73^{*}$ & $119.02 \pm 23.17 \dagger, \#$ & $<0.0001$ \\
\hline BS -BL delay by LS & $47.03 \pm 9.31$ & $102.67 \pm 21.62^{*}$ & $113.88 \pm 40.69 \dagger, \#$ & $<0.0001$ \\
\hline Sdt 12 s by LS & $52.96 \pm 5.15$ & $90.03 \pm 16.29^{*}$ & $111.75 \pm 34.22 \dagger, \#$ & $<0.0001$ \\
\hline
\end{tabular}

LBBB, left bundle branch block; SDI, systolic dyssynchrony index;AS-P delay - difference between time to peak systolic strain of the anteroseptal and posterior segments; BS-BL delay - difference between time to peak systolic strain of the basal-septal and basal lateral segments; CS - circumferential strain; LS - longitudinal strain; sdt6sstandard deviation of the time to peak systolic strain of 6 segments; sdt12s - standard deviation of the time to peak systolic strain of 12 segments;

* Significant difference non-LBBB volunteers versus Asymptomatic LBBB.

$\dagger$ Significant difference non- LBBB volunteers versus symptomatic LBBB.

\# Significant difference asymptomatic LBBB versus symptomatic LBBB.

Figure D:- Standard deviation of time to peak-systolic strain for all 6 segments (sdt6s) by speckle tracking.

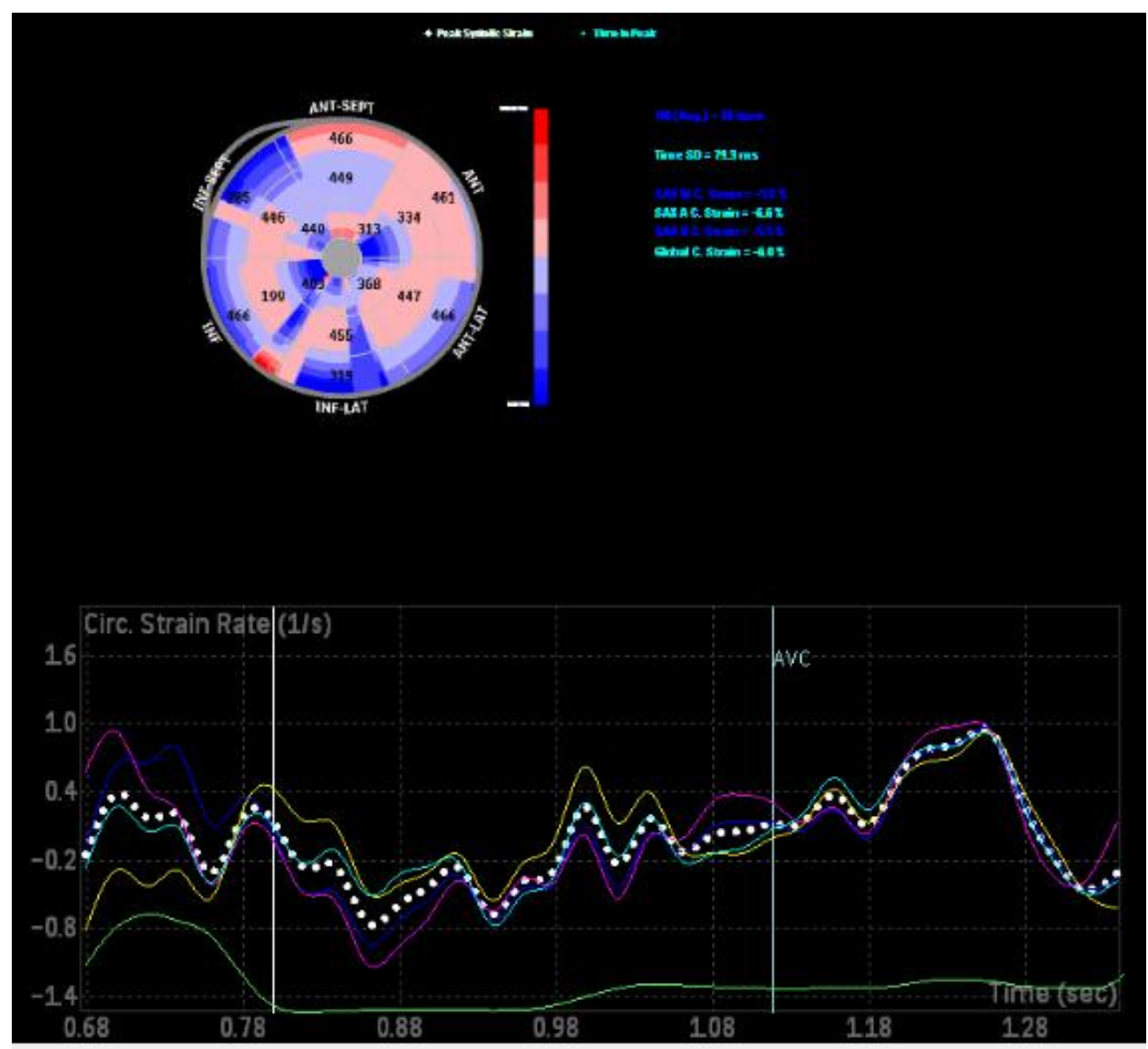




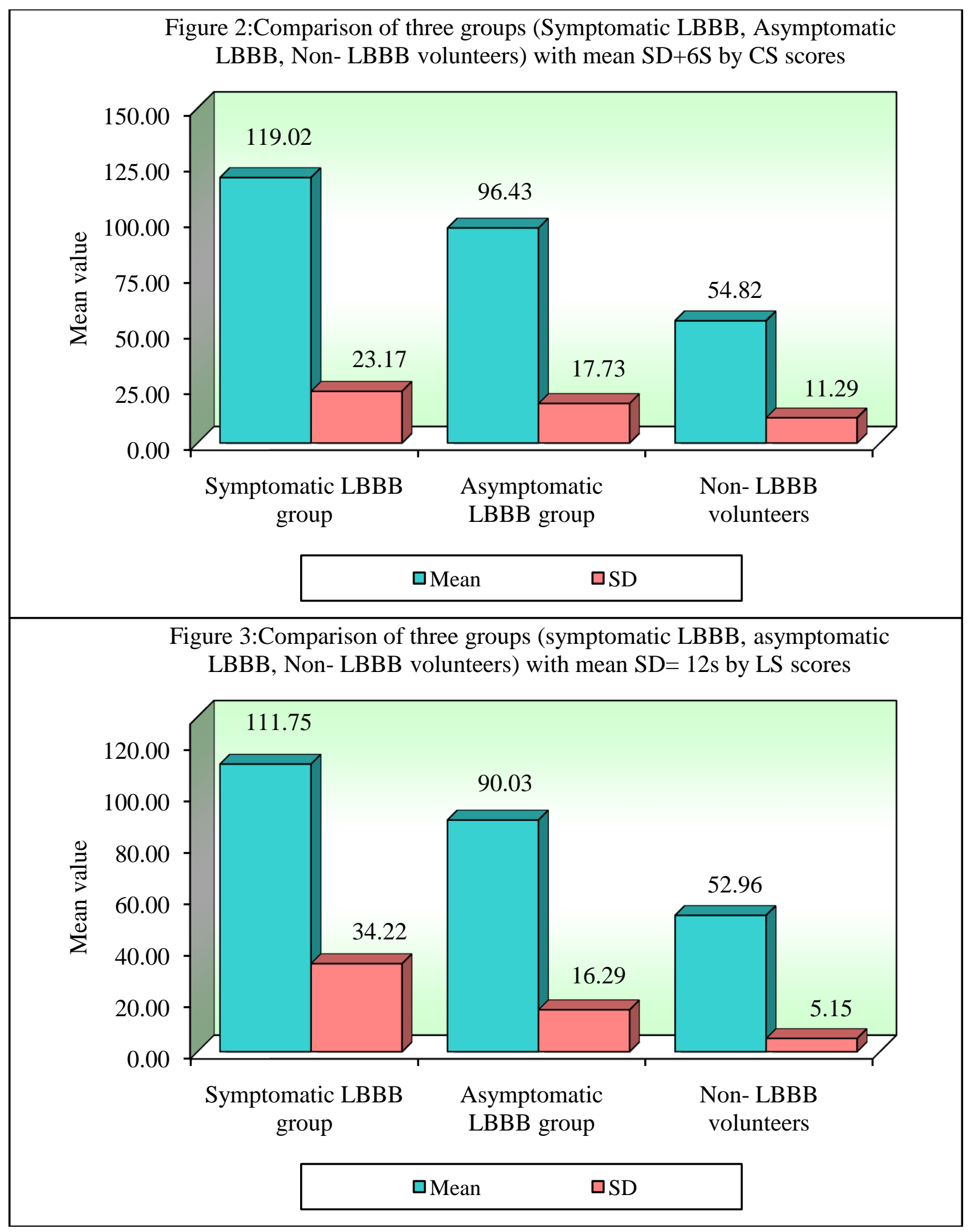




\section{Discussion:-}

Important finding of this study is that, 2D Echocardiography, 2D speckle tracking, RT 3D Echo are useful for detecting differences in global LV function and mechanical LV dyssynchrony in LBBB patients with or without symptoms compared to non- LBBB volunteers.

Assessment of global LV function demonstrated that patients with asymptomatic LBBB and patients with symptomatic LBBB had a mild and moderate to severe reduction in EF respectively.

The EF, EDV, ESV measured with RT 3D Echo was lesser than one would expect when conventional 2D Echocardiography is used.

Mechanical dyssynchrony assessed by RT 3D Echo and speckle tracking strain analysis showed that non-LBBB volunteers had mild mechanical dyssynchrony. In asymptomatic LBBB patients intermediate mechanical dyssynchrony was observed and in symptomatic LBBB patients severe mechanical dyssynchrony was noted, which differed significantly among these 3 groups.

As observed previously in other studies, the EF and the amount of mechanical dyssynchrony showed an inverse correlation. ${ }^{20}$ In accordance with results of a study by Vernooyet al., ${ }^{1}$ the trend to increased mechanical dyssynchrony in asymptomatic LBBB patients and the significant increased mechanical dyssynchrony in symptomatic LBBB patients in the present study, might be held responsible for the observed mild global LV dysfunction in asymptomatic LBBB patients and moderate to severe global LV dysfunction in symptomatic LBBB patients . Thus, demonstrating that mechanical dyssynchrony might negatively affect LV function and the resulting symptomatic status.

A study conducted by Kapetanakis et al. ${ }^{20}$ showed HF with symptomatic LBBB patients with severe LV dysfunction had SDI of $15.7 \pm 6.7$ which was in accordance with SDI of $15.08 \pm 3.85$ in our symptomatic LBBB patients.

Another study conducted by Jeroen van dijk et al. ${ }^{28}$ found SDI of $12.8 \pm 4.8$ in HF patients with LBBB which was in accordance with SDI of $15.08 \pm 3.85$ in our study.

In our study, number of LBBB patients enrolled is larger when compared to other older studies. It is also one of the first of its kind where LBBB patients are evaluated to assess global LV function and mechanical dyssynchrony in comparison to non- LBBB volunteers by means of 2D Echocardiography, 2D Speckle tracking strain analysis and 3D Echocardiography.

\section{Clinical implications:-}

With evaluation of LBBB patients with and without symptoms, differences in global LV function and mechanical dyssynchrony was observed which suggested that patients with a LBBB, who achieve a certain amount of mechanical dyssynchrony, may develop symptomatic HF. Therapeutic interventions that will decrease mechanical dyssynchrony may lead to a reduction of symptoms and improvement in LV function.

\section{Study limitations:-}

In patients with a LBBB, it is often unknown for how long a LBBB has been present. The process of remodelling of the LV that might occur after the formation of a LBBB, may be more distinct in a patient with a long lasting LBBB, than in a patient with a new onset LBBB.

In RT3DE, frame rates are relatively low $(20-25 \mathrm{~Hz})$ compared to tissue Doppler imaging $(100-150 \mathrm{~Hz})$. For evaluation of mechanical dyssynchrony, low frame rates can be a limitation in detecting very subtle dyssynchrony differences between the segments. However, RT3DE acquisitions have high spatial resolution and post-processing analysis can be done fast with good reproducibility, compared to other imaging techniques. ${ }^{21-23}$ 


\section{Conclusion:-}

2D Echocardiography, 2D Speckle tracking strain analysis and 3D Echocardiographic evaluation of LBBB patients with or without symptoms and non-LBBB volunteers showed that global LV function of asymptomatic LBBB patients already slightly impaired compared to non- LBBB volunteers. However it was observed that patients with symptomatic LBBB have most severely impaired LV function.

Based on global LV function analysis in all 3 groups by 2D Echocardiography and real time 3D Echocardiography found that the values observed by real time 3D Echocardiography were significantly lesser when compared to 2D Echocardiography as 2D Echo considers LV in the form of a cylinder. Whereas, real time 3D Echocardiography during measurements take endocardial contours which are semi-automatically detected during the complete cardiac cycle creating a LV cast which is used to measure the LV volumes and EF. Hence real time 3D Echocardiography is more accurate and standardised method when compared to 2D Echocardiography.

Mechanical LV dyssynchrony in asymptomatic LBBB patients is already increased and patients with symptomatic LBBB have the more severe mechanical dyssynchrony.

Quantification of mechanical dyssynchrony with 2D speckle tracking strain imaging and RT3DE is useful, as increased mechanical dyssynchrony might have an effect on global LV dysfunction and consequential symptoms. $\mathrm{EF}$ and the amount of mechanical dyssynchrony showed an inverse correlation in our study indicating that when a substantial level of LV mechanical dyssynchrony is reached, it might be suggestive for the presence of symptoms.

\section{References:-}

1. Vernooy K, Verbeek XA, Peschar M, Crijns HJ, Arts T, Cornelussen RN et al. Left bundle branch block induces ventricular remodelling and functional septal hypoperfusion. Eur Heart J 2005;26

2. Bader H, Garrigue S, Lafitte S, Reuter S, Jais P, Haissaguerre M et al. Intra-left ventricular electromechanical asynchrony. A new independent predictor of severe cardiac events in heart failure patients. J Am Coll Cardiol 2004;43:248 -56.

3. Baldasseroni S, Opasich C, Gorini M, Lucci D, Marchionni N, Marini M et al. Left bundle-branch block is associated with increased 1-year sudden and total mortality rate in 5517 outpatients with congestive heart failure: a report from the Italian network on congestive heart failure. Am Heart J 2002;143:398 -405.

4. Fahy GJ, Pinski SL, Miller DP, mccabe N, Pye C, Walsh MJ et al. Natural history of isolated bundle branch block. Am J Cardiol 1996;77

5. Iuliano S, Fisher SG, Karasik PE, Fletcher RD, Singh SN. QRS duration and mortality in patients with congestive heart failure. Am Heart J 2002;143

6. Ozdemir K, Altunkeser BB, Danis G, Ozdemir A, Uluca Y, Tokac M et al. Effect of the isolated left bundle branch block on systolic and diastolic functions of left ventricle. J Am Soc Echocardiogr 2001;14

7. Grines CL, Bashore TM, Boudoulas H, Olson S, Shafer P, Wooley CF. Functional abnormalities in isolated left bundle branch block. The effect of interventricular asynchrony. Circulation 1989;79

8. Melek M, Esen O, Esen AM, Barutcu I, Onrat E, Kaya D. Tissue Doppler evaluation of intraventricular asynchrony in isolated left bundle branch block. Echocardiography 2006;23

9. Bax JJ, Bleeker GB, Marwick TH, Molhoek SG, Boersma E, Steendijk P et al. Left ventricular dyssynchrony predicts response and prognosis after cardiac resynchronization therapy. J Am Coll Cardiol 2004;44:1834 -40.

10. Kass DA. Ventricular resynchronization: pathophysiology and identification of responders. Rev Cardiovasc Med 2003;4 (Suppl 2):S3 -S13.

11. Yu CM, Zhang Q, Fung JW, Chan HC, Chan YS, Yip GW et al. A novel tool to assess systolic asynchrony and identify responders of cardiac resynchronization therapy by tissue synchronization imaging. J Am Coll Cardiol 2005; 45

12. Caiani EG, Corsi C, Zamorano J, Sugeng L, maceneaney P, Weinert L et al. Improved semiautomated quantification of left ventricular volumes and ejection fraction using 3-dimensional echocardiography with a full matrix-array transducer: comparison with magnetic resonance imaging. J Am Soc Echocardiogr 2005; 18:779-88.

13. Corsi C, Lang RM, Veronesi F, Weinert L, Caiani EG, maceneaney P et al. Volumetric quantification of global and regional left ventricular function from real-time three-dimensional echocardiographic images. Circulation 2005; 112:1161 -70. 
14. Kuhl HP, Schreckenberg M, Rulands D, Katoh M, Schafer W, Schummers G et al. High-resolution transthoracic real-time three-dimensional echocardiography: quantitation of cardiac volumes and function using semiautomatic border detection and comparison with cardiac magnetic resonance imaging. J Am Coll Cardiol 2004;43

15. Mannaerts HF, Van Der Heide JA, Kamp O, Papavassiliu T, Marcus JT, Beek A et al. Quantification of left ventricular volumes and ejection fraction using freehand transthoracic three-dimensional echocardiography: comparison with magnetic resonance imaging. J Am Soc Echocardiogr 2003;16:101 -9.

16. Kapetanakis S, Cooklin M, Monaghan MJ. Mechanical resynchronisation in biventricular pacing illustrated by real time transthoracic three dimensional echocardiography. Heart 2004;90

17. Van Der Heide JA, Mannaerts HF, Spruijt HJ, van Campen LM, de Cock C, Visser CA et al. Noninvasive mapping of left ventricular electromechanical asynchrony by three-dimensional echocardiography and semiautomatic contour detection. Am J Cardiol 2004;94:1449 -53.

18. Zhang Q, Yu CM, Fung JW, Zhang Y, Chan YS, Chan HC et al. Assessment of the effect of cardiac resynchronization therapy on intraventricular mechanical synchronicity by regional volumetric changes. Am $\mathrm{J}$ Cardiol 2005; 95

19. Schiller NB, Shah PM, Crawford M, demaria A, Devereux R, Feigenbaum H et al. Recommendations for quantitation of the left ventricle by twodimensional echocardiography. American Society of Echocardiography Committee on Standards, Subcommittee on Quantitation of twodimensional Echocardiograms. J Am Soc Echocardiogr 1989;2

20. Kapetanakis S, Kearney MT, Siva A, Gall N, Cooklin M, Monaghan MJ. Realtime three dimensional echocardiography: a novel technique to quantify global left ventricular mechanical dyssynchrony. Circulation 2005;112: 992 - 1000.

21. Bax JJ, Ansalone G, Breithardt OA, Derumeaux G, Leclercq C, Schalij MJ et al. Echocardiographic evaluation of cardiac resynchronization therapy: ready for routine clinical use? A critical appraisal. Jamcoll Cardiol 2004;44

22. Monaghan MJ. Role of real time 3D echocardiography in evaluating the left ventricle. Heart 2006;92:131 -6.

23. Yu CM, Fung JW, Zhang Q, Chan CK, Chan YS, Lin H et al. Tissue Doppler imaging is superior to strain rate imaging and postsystolic shortening on the prediction of reverse remodeling in both ischemic and nonischemic heart failure after cardiac resynchronization therapy. Circulation 2004; 110

24. Eriksson P, Hansson PO, Eriksson H, Dellborg M. Bundle-branch block in a general male population: the study of men born 1913. Circulation 1998;98:2494-500.

25. Imanishi R, Seto S, Ichimaru S, Nakashima E, Yano K, Akahoshi M. Prognostic significance of incident complete left bundle branch block observed over a 40-year period. Am J Cardiol 2006; 98:644.

26. Rotman M, Triebwasser JH. A clinical and follow-up study of right and left bundle branch block. Circulation 1975;51:477.

27. Perk G, Tunick PA, Kronzon I. Non-Doppler two-dimensional strain imaging by echocardiography-from technical considerations to clinical applications. J Am Soc Echocardiogr 2007;20:234 -43.

28. Jeroen van Dijk, Pieter A. Dijkmans et al Evaluation of global left ventricular function and mechanical dyssynchrony in patients with an asymptomatic left bundle branch block: a real-time 3D echocardiography study. European Journal of Echocardiography (2008) 9. 